\title{
Sieben Erkenntnisse aus der Pandemie
}

\begin{abstract}
Wir Richter können in Krisen auf Fähigkeiten zurückgreifen, die wir im Berufsalltag entwickelt haben. Dank unserer Erfahrung mit Gesuchen um vorsorgliche Massnahmen können wir Unsicherheiten aushalten. Aus Urteilsberatungen kennen wir das Konzept der Wirklichkeitskonstruktion und die Tücken des deduktiven Denkens. Der vorliegende Beitrag legt dar, wo wir in Krisen dazulernen können. Vom amerikanischen Physiker David Bohm erfahren wir, wie wir besser zuhören. Piloten zeigen uns, wie wichtig Vertrauen in Entscheidungssituationen ist. Und von Führungspersönlichkeiten lernen wir, wo sich Vertrauen lohnt.
\end{abstract}

Beitragsart: Forum

Zitiervorschlag: Martin Kayser, Sieben Erkenntnisse aus der Pandemie, in: «Justice - Justiz Giustizia» 2020/4 


\section{Inhaltsübersicht}

1. Unsicherheiten aushalten

2. Patendlösungen misstrauen

3. Abwägen und entscheiden - frei nach Kant

4. Wirklichkeitskonstrukte dekonstruieren

5. Stille ertragen

6. Zutrauen finden

7. Alles Leben ist Lernen

\section{Unsicherheiten aushalten}

[1] In der gegenwärtigen Krise können wir einiges lernen. Dabei können wir Richter in ein paar Punkten an Dinge anknüpfen, die wir ausserhalb von Krisen in unserem Berufsalltag erproben. Als Erstes gehört die Fähigkeit dazu, Unsicherheiten auszuhalten.

[2] Wir müssen nicht die perfekte Entscheidung fällen. Vielmehr müssen wir rasch entscheiden, auch wenn uns dabei noch nicht alle Informationen zur Verfügung stehen. Ob wir Mitarbeiter nach Hause schicken, Gerichtsverhandlungen online durchführen oder selbst von zu Hause aus arbeiten, entscheiden wir frei nach Karl Popper ${ }^{1}$ gestützt auf den gegenwärtigen Stand des Irrtums.

[3] In einer solchen Situation haben wir Richter einen Vorteil. Wir entscheiden regelmässig über provisorische Massnahmen. Bei solchen Gesuchen wissen wir in der Regel nur sehr wenig. Der Gesuchsteller behauptet dieses, der Gesuchsgegner etwas ganz anderes. Wir dürfen unseren Entscheid deswegen nicht aufschieben. Vielmehr treffen wir eine Wertung, bei der wir uns bewusst sind, dass sie nicht für alle Ewigkeit gelten wird.

[4] Der in Deutschland gebräuchliche Ausdruck des einstweiligen Rechtsschutzes trifft das, was wir in solchen Situationen tun, besser. Wir entscheiden bloss für die kommenden Tage und Wochen. Sobald wir mehr wissen, beurteilen wir die Lage neu. Und auch dann ist unser Prognoseentscheid immer nur einstweilig. ${ }^{2}$ Definitiv wird er nie. Vielleicht kommen wir in unserem Endurteil zu einem ähnlichen Schluss wie seinerzeit beim Entscheid über die vorsorglichen Massnahmen. Das ist aber dann letztlich blosser Zufall.

[5] Dass wir zu Beginn der Krise die Lage anders beurteilten als später, hat somit nichts mit Wankelmütigkeit zu tun. Wir wurden im Laufe der Krise ganz einfach gescheiter. Dachten wir zu Beginn, dass wir Oberflächen unter keinen Umständen berühren sollten, vermutet die Wissenschaft heute, dass so genannte «Schmierinfektionen» nur selten auftreten. ${ }^{3}$ Meinten wir am Anfang der Krise, uns durch Abstandhalten in jedem Fall schützen zu können, müssen wir heute davon ausgehen, dass sich das Virus in geschlossenen, schlecht belüfteten Räumen auch über weitere Distanzen verbreiten kann. ${ }^{4}$ Anfangs dachten wir, dass allein die so genannten «Risiko-

1 Vgl. Karl Popper, Die Logik der Forschung (1935), 11. Aufl. Tübingen 2005, S. 18, 57 (zur Möglichkeit der Falsifikation einer Theorie, die auf einem Irrtum beruht).

2 Illustrativ Andreas Vosskuhle, Die Zumutungen der Prognose, in: Bernd Kortmann/Günther G. Schulze (Hrsg.), Jenseits von Corona, Bielefeld 2020, S. 205 ff., 207 f.

3 Vgl. Emanuel Goldman, Exaggerated risk of transmission of COVID-19 by fomites, The Lancet 2020, S. 892 f., www.thelancet.com/journals/laninf/article/PIIS1473-3099(20)30561-2/fulltext. Sämtliche der in diesem Beitrag zitierten Webseiten wurden zuletzt am 25. November 2020 besucht.

4 Wie häufig die Verbreitung über Aerosole ist, kann zurzeit nicht beziffert werden; vgl. Elizabeth LeE u.a., The engines of SARS-CoV-2 spread, Science 2020, S. 406 f., https://science.sciencemag.org/content/370/6515/406. 
gruppen» vom Virus betroffen sind. Mit der Zeit mussten wir erkennen, dass nicht nur unser Alter oder unsere Vorerkrankungen eine Rolle spielen, sondern auch die Dosis, die wir einatmen. ${ }^{5}$ Anfangs wurde uns gesagt, dass Masken nichts bringen. ${ }^{6}$ Spätestens seit April wissen wir, dass sie andere im Verbund mit weiteren Vorsichtsmassnahmen wirksam schützen. ${ }^{7}$ Im Frühjahr glaubten wir noch, dass nur Menschen mit Symptomen ansteckend sind. Heute wissen wir, dass die Zeit unmittelbar vor dem Auftreten von Symptomen die ansteckendste sein kann. ${ }^{8}$

[6] Dauernd gescheiter zu werden darf indessen kein Vorwand sein, um nichts zu tun. Über vorsorgliche Massnahmen entscheiden wir besser bereits heute als morgen. Für die perfekte Entscheidung bleibt kein Raum. In der Krise noch viel weniger. Die Parteien müssen rasch erfahren, ob wir die Verhandlung vor Ort oder auf elektronischem Weg durchführen. Wenn einer unserer Mitarbeiter sein Büro mit anderen teilt, müssen wir für ihn heute ein Einzelbüro finden. Wenn unsere Beschäftigten lange Anfahrtswege haben, müssen wir ihnen jetzt die Möglichkeit zum Home-Office einräumen.

[7] Vor diesem Hintergrund waren die beinahe epischen Diskussionen über das Maskentragen nicht nachvollziehbar. Aus der Perspektive des Massnahmerichters erscheint ein Mund-NaseSchutz als probates Mittel, um das Risiko von Ansteckungen für andere zu reduzieren. Um wie viele Prozente wir damit das Risiko in welchen Situationen vermindern, lässt sich heute naturgemäss nicht exakt beziffern. ${ }^{9}$ Genaue Werte benötigen wir im Massnahmenverfahren allerdings nicht. Es genügt vielmehr die Wahrscheinlichkeit, dass wir damit die Gesundheit anderer schützen. ${ }^{10}$ Selbst wenn wir eines Tages wissen, dass Gesichtsmasken nur wenig gegen die Weiterverbreitung des Virus halfen, war unser derzeitiger Entscheid deswegen nicht falsch. Vielmehr tasten wir uns wie in der Forschung auch ${ }^{11}$ dem gegenwärtigen Irrtum entlang.

[8] Wir müssen dabei lernen, Unsicherheiten auszuhalten. Letztere dürfen unsere Entscheidungsfreude nicht vermindern. Die ständige Unsicherheit ist vielmehr Teil der Krise und bleibt letztlich die einzige Gewissheit. Das müssen wir so akzeptieren. Je nach Position, die wir an unserem Gericht innehaben, können wir von alledem nur einen verschwindend kleinen Teil beeinflussen.

full; Centers for Disease Control and Prevention, SARS-CoV-2 and Potential Airborne Transmission, www.cdc.gov /coronavirus/2019-ncov/more/scientific-brief-sars-cov-2.html.

5 Vgl. Elisabet Pujadas u.a., SARS-CoV-2 viral load predicts COVID-19 mortality, The Lancet 2020, S. e70 (Respiratory), www.thelancet.com/journals/lanres/article/PIIS2213-2600(20)30354-4/fulltext.

6 So noch bis Ende März verschiedene Vertreter des Bundesamts für Gesundheit; vgl. Recherche-desk Tamedia, Lockdown, Lachen 2020, S. 201. Tendenziell anders schliesslich Daniel Косн in einem Interview vom Juli 2020, a.a.O., S. $287 \mathrm{f}$.

7 Vgl. Jeremy Howard u.a., Face Masks Against COVID-19: An Evidence Review (Erstfassung veröffentlicht am 12. April 2020, www.preprints.org/manuscript/202004.0203/v1). Beim zitierten Beitrag handelt es sich um eine Meta-Studie; dass Masken schützen, wiesen diverse Beiträge lange vor April 2020 nach.

8 Erschwerend kommt hinzu, dass viele erkrankte Menschen überhaupt nie Symptome zeigen. Das heisst allerdings nicht unbedingt, dass sie nicht ansteckend wären. Vgl. Irene Petersen/Andrew Phillips, Three Quarters of People with SARS-CoV-2 Infection are Asymptomatic: Analysis of English Household Survey Data, Clinical Epidemiology 2020, S. 1039 ff., https:/ / www.dovepress.com/three-quarters-of-people-with-sars-cov-2-infection-areasymptomatic-an-peer-reviewed-fulltext-article-CLEP.

9 Vgl. etwa Lynne Peeples, Face masks: what the data say, Nature 586/2020, S. 186 ff., www.nature.com/articles /d41586-020-02801-8.

10 Vgl. etwa BGE 130 II 149 E. 2.3 (summarische Prüfung ohne eingehende Beweismassnahmen im vorsorglichen Massnahmeverfahren) sowie E. 3.4 (für einen nicht leicht wiedergutzumachenden Nachteil muss eine gewisse Wahrscheinlichkeit dargetan werden).

11 Vorn Fn. 1. 
Auf diesen müssen wir uns konzentrieren. Alles andere hiesse, im Schockzustand zu verharren, in den wir Ende Februar 2020 hineingerieten.

\section{Patendlösungen misstrauen}

[9] Viele von uns haben vielleicht eine Urteilsberatung erlebt, bei der sich die Fronten zusehends verhärteten. Der Kollege beantragt die Gutheissung der Beschwerde und damit die Kassation des angefochtenen Entscheids. Gehörsverletzungen dürften «a priori» nicht geheilt werden; das Gericht sei schliesslich kein Spital. ${ }^{12}$ Die Kollegin entgegnet, sie sei «aus Prinzip» gegen die formelle Natur. Unsere Aufgabe sei es, «pragmatisch» und nicht «dogmatisch» zu befinden.

[10] Die Beteiligten haben sich auf diese Weise im Grundlegenden eingegraben. Der Einzelfall gerät aus dem Blick, und für eine kongruente Weiterentwicklung der Rechtsprechung wird der Raum schmaler und schmaler.

[11] In der gegenwärtigen Krise ist es manchmal leider nicht anders. Die einen fanden, dass man nur mit einer Null-Risiko-Politik weiterkomme. Jedes Menschenleben zähle. Dafür sei jeder Eingriff in unsere Freiheiten gerechtfertigt. Schliesslich habe Neuseeland mit seiner Strategie der Ausrottung Erfolg gehabt. Die Premierministerin verhängte dort einen strikten Lockdown, als die Zahl der Infizierten noch knapp über 100 lag und Neuseeland keinen einzigen Toten zu beklagen hatte. ${ }^{13}$ Nach nur fünf Wochen konnte der Lockdown gelockert werden. Am 8. Juni 2020 konnte eine stolze Premierministerin vermelden, dass das Virus dank der drastischen Massnahmen habe beseitigt werden können. ${ }^{14}$ Neuseeland hatte während der ersten Welle allein 22 Tote zu beklagen. ${ }^{15}$ Die harten Massnahmen, so die Vertreter der Null-Risiko-Politik, seien Beweis dafür, dass das Virus so «besiegt» werden könne.

[12] Auf der anderen Seite des Spektrums stehen die Befürworter der Herdenimmunität. Ihnen zufolge ist jede staatliche Massnahme von vornherein fehlgeleitet. Wir Gesunden sollen uns frei bewegen und das Virus möglichst schnell verbreiten. So würden die meisten von uns schon bald gegen das Virus immun sein. Auf diese Weise werde es Geschichte.

[13] Popularisiert wurde die Theorie durch Maureen Eames. Die 83-Jährige gab einem BBCReporter beim Einkaufen zu Protokoll, sie lasse sich von den Beschränkungen in South Yorkshire nicht beeindrucken. ${ }^{16}$ Sie habe den Krieg überstanden; da mute es lächerlich an, wegen eines Virus so viel Aufhebens zu machen. Monate zuvor hatte bereits der italienische Philosoph Agamben

12 Es versteht sich von selbst, dass sich die hier wiedergegebene Beratung in dieser Form nicht zugetragen hat. Zum Schutz des Beratungsgeheimnisses fasse ich an dieser Stelle Aussagen von Konferenzen, Seminaren und Urteilsberatungen zusammen.

13 Vgl. Anna Jones, How did New Zealand become Covid-19 free?, BBC News vom 9. Juli 2020, www.bbc.com/news /world-asia-53274085.

14 Vgl. Damien Cave, New Zealand Lifts Lockdown as It Declares Virus Eliminated, for Now, New York Times vom 8. Juni 2020, www.nytimes.com/2020/06/08/world/australia/new-zealand-coronavirus-ardern.html.

15 Vgl. die Informationen des neuseeländischen Gesundheitsministeriums vom 31. Mai 2020; https://web. archive.org/web/20200531023715/https://www.health.govt.nz/our-work/diseases-and-conditions/ covid-19-novel-coronavirus/covid-19-current-situation/covid-19-current-cases.

16 Vgl. www.reuters.com/article/health-coronavirus-britain-pensioner/im-83-i-dont-give-a-sod-uk-pensioner-sums -up-frustration-with-new-covid-curbs-idUSL8N2HD43D. 
in seinem Heimatland ${ }^{17}$ und der Schweiz ${ }^{18}$ beklagt, dass uns jegliches Augenmass abhandengekommen sei. Es sei ungeheuerlich, dass wir durch das ständige Abstandhalten unsere Freiheiten aufgeben. ${ }^{19}$ Nicht einmal unsere Toten könnten wir mehr anständig begraben. All dies geschehe, weil wir nicht mehr bereit seien, an irgendetwas zu glauben - ausser «an das nackte biologische Überleben ${ }^{20}$.

[14] Beide Positionen wirkten auf den ersten Blick bestechend einfach. Wenn man wie in Neuseeland strenge Massnahmen verhängt, kann man das Virus bezwingen. Man schützt so die Gesundheit aller. Wenn man umgekehrt das Leben weiterführt wie bisher, bezwingt man es ebenfalls. Man braucht dafür bloss ein bisschen länger als Neuseeland. Ausserdem bleiben einem dabei die enormen wirtschaftlichen Schäden erspart, die ein Lockdown anrichtet.

[15] Nun brauchte man nicht sehr lange, um die Irrlichter am Ende der beiden Positionen zu erkennen. Wirtschaft und Gesundheit werden zu Gegensätzen emporstilisiert, die sie nicht sind. ${ }^{21}$ Die Null-Risiko-Vertreter wollen offenbar darüber hinweggehen, dass Neuansteckungen schlicht unvermeidbar sind. Selbst wenn man das Virus auf einer Insel ausrotten könnte, bliebe dieser Zustand nur solange von Dauer, als man seinen eigenen Bürgern und allen anderen die Einreise verbieten wollte. Quarantäne-Massnahmen mögen hier zwar eine gewisse Sicherheit bieten; einen absoluten Schutz gewährleisten sie nicht. Vertreter einer Null-Risiko-Politik lassen sodann die Frage offen, wie wir bis zur flächendeckenden Einführung eines wirksamen Impfstoffes oder wenigstens eines Heilmittels weiterleben sollen. Uns alle einzuschliessen, erscheint kaum als gangbarer Weg. Seit Beginn der Krise ist die Frage nicht die, $o b$ noch weitere Menschen am Virus sterben, sondern wie viele.

[16] Agamben scheint demgegenüber davon auszugehen, dass Herdenimmunität in absehbarer Zeit zu erreichen wäre. Dabei geht er über Studien hinweg, nach denen es bis zu einer Durchseuchung der Bevölkerung, wenn überhaupt, ${ }^{22}$ erst nach Jahren oder gar Jahrzehnten kommt. ${ }^{23}$ Was ältere und vorerkrankte Menschen in dieser Zeit mit sich anfangen sollen, können uns die Vertreter der Immunitätstheorie nicht plausibel beantworten. Einige meinten, man solle Angestellten von Alters- und Pflegeheimen bis zur rettenden Durchseuchung der Bevölkerung mehr Lohn zahlen, damit sie sich zusammen mit den Bewohnern isolieren können. In dieser Zeit könnten die Gesunden ihren Alltag normal weiterleben. Die anderen Menschen aus Risikogruppen, die nicht in Heimen leben, sollen in dieser Zeit keine Kontakte pflegen. Wie durch ein Wunder

17 Giorgio Agamben, Lo stato d'eccezione provocato da un'emergenza immotivata, Il manifesto vom 26. Februar 2020, https://ilmanifesto.it/lo-stato-deccezione-provocato-da-unemergenza-immotivata/.

18 Exemplarisch Giorgio Agamben, Ich hätte da eine Frage, NZZ vom 15. April 2020, www.nzz.ch/feuilleton /coronavirus-giorgio-agamben-zum-zusammenbruch-der-demokratie-ld.1551896.

19 So bereits Giongio Agamben, Nach Corona: Wir sind nurmehr das nackte Leben, NZZ vom 18. März 2020, www.nzz.ch/feuilleton/giorgio-agamben-ueber-das-coronavirus-wie-es-unsere-gesellschaft-veraendertld.1547093.

20 Giorgio Agamben, Wir sollten uns weniger sorgen und mehr denken, NZZ vom 7. April 2020, www.nzz.ch /feuilleton/giorgio-agamben-zur-coronakrise-wir-sollten-uns-weniger-sorgen-und-mehr-nachdenken-ld.1550672.

21 Vgl. Raj Chetry u.a., The Economic Impacts of COVID-19: Evidence from a New Public Database Built Using Private Sector Data (Stand: November 2020), S. 4, 19 f., 41, https://opportunityinsights.org/wp-content/uploads/ 2020/05/tracker_paper.pdf; Fareed ZaKaria, Ten Lessons for a Post-Pandemic World, New York 2020, S. 151 ff. Zum gegenwärtigen Stand der Forschung statt vieler Christie Aschwanden, The false promise of herd immunity for COVID-19, Nature vom 21. Oktober 2020, www.nature.com/articles/d41586-020-02948-4.

23 Vgl. Eric J W Orlowski/David J A Goldsmith, Four Months into the COVID-19 Pandemic, Sweden's Prized Herd Immunity Is Nowhere in Sight, Journal of the Royal Society of Medicine 2020, S. $292 \mathrm{ff}$. Vgl. auch Michael Le PAge, Is Sweden's coronavirus strategy a cautionary tale or a success story?, New Scientist, www.newscientist.com/article /2251615-is-swedens-coronavirus-strategy-a-cautionary-tale-or-a-success-story/. 
wird sich die Welt also in zwei Kontinente teilen. Auf dem einen leben die Gesunden, auf dem anderen die Alten, Kranken und Gebrechlichen. Mögen solche Vorschläge zu Beginn der Krise noch ein verzweifelter Hilfeschrei gewesen sein, ${ }^{24}$ erscheinen sie heute schlicht realitätsfern.

[17] Nun haben die Vertreter der beiden Fundamentalpositionen etwas gemein. Beide führen sie die goldene Regel ad absurdum. «Was ihr von anderen erwartet, das tut ebenso auch ihnen.» ${ }^{25}$ Weil Agamben das Risiko des Virus als «nicht näher zu bestimmend» ${ }^{26}$ erachtet, braucht er sich von einer Ansteckung nicht zu fürchten. Weil Frau Eames und ihr Mann das Virus ohne nachhaltige gesundheitliche Probleme überlebten, sollen sich die anderen doch bitteschön nicht so anstellen. ${ }^{27}$ Aus Sicht von Agamben und Eames geht diese Rechnung auf. Ältere und kranke Menschen, die weniger Glück hatten, würden es wahrscheinlich anders sehen.

[18] Die Vertreter der Null-Risiko-Theorie wiederum sind nicht bereit, noch mehr Tote in Kauf zu nehmen. Menschenleben verdienen absoluten Schutz, und zwar um jeden Preis. Wer selbst ein hohes Risiko eingeht, bei einer Infektion schweren Schaden anzunehmen, hat mit diesem Ansatz aus einer Perspektive recht. Er versteht wie die Vertreter der anderen Fundamentalposition die goldene Regel absolut. ${ }^{28}$ Nach so einem wörtlichen Verständnis der Regel könnte es der Masochist rechtfertigen, anderen Leid zuzufügen, da er selbst Schmerzen gerne in Kauf nimmt. Der junge Gesunde darf anderen zu nahe kommen, da er bei einer Infektion wenig zu befürchten hat. ${ }^{29}$ Und wer einer Risikogruppe angehört, darf von der Regierung einen weiteren Lockdown einfordern.

[19] Die Fundamentalpositionen haben ein Weiteres gemein: Sie deduzieren. Weil der Tod unvermeidlich ist, brauchen wir ihn nicht zu fürchten. Weil wir ihn nicht zu fürchten brauchen, müssen wir auch keinen Abstand halten. Oder: Weil jeder Tote zu vermeiden ist, müssen wir das Virus um jeden Preis eindämmen. Weil die totale Ausrottung des Virus um jeden Preis notwendig ist, müssen wir immer zu Hause bleiben. Weil der Verbleib in den eigenen vier Wänden die einzige Lösung ist, müssen wir das solange durchhalten, bis das Virus vollständig «besiegt» ist. All dies, so beide Vertreter, gilt unabhängig davon, wie viele Betten auf den Notfallstationen verbleiben.

[20] Aus Urteilsberatungen wissen wir, dass deduktive Argumentationen selten zum Ziel führen. Weil das rechtliche Gehör wichtig ist, darf es nicht verletzt werden. Weil es nicht hätte verletzt werden dürfen, müssen wir den angefochtenen Entscheid kassieren. Oder: Weil Verfahrensrechte keinen Selbstzweck besitzen, kann dem Gehörsanspruch nur dienende Funktion zukommen. Weil der Anspruch nur dienenden Charakter hat, darf er folgenlos verletzt werden. Weil die Verletzung

24 Prononciert die Reaktion auf Agambens Thesen (Rn. 13) in Italien; vgl. nur Paolo Flores D'ArCAIs, Filosofia e virus: le farneticazioni di Giorgio Agamben, MicroMega vom 16. März 2020, http://temi.repubblica.it/micromegaonline/filosofia-e-virus-le-farneticazioni-di-giorgio-agamben/?refresh_ce.

Lukas 6, 31. Ähnlich Matthäus 7,12 («Alles, was ihr also von anderen erwartet, das tut auch ihnen!»).

26 Agamben (Fn. 18)

27 Michael Eames steckte sich mit dem Virus Ende Februar 2020 an. Zunächst hustete er Blut, erholte sich dann aber anfangs Mai wieder. Maureen Eames hatte Schmerzen in ihrer Brust, war nach zehn Tagen aber schon wieder gesund. Gegenüber den Journalisten gab sie zu Protokoll: «We should never have been in lockdown. All the people who were vulnerable should have been helped and kept home safe. And all the rest of us, I'm 83, I don't give a sod. What they should have done was ensure that all the old people and the people who have health problems were protected and if they wanted anything there was someone there to take it to the house. Then they let the rest of us get on with life.» www.telegraph.co.uk/news/2020/10/22/should-not-surrender-warns-grandmother-became -overnight-celebrity/.

28 Dass die goldene Regel anders gemeint ist, als von den Fundamentalpositionen gelegentlich angenommen, zeigt Helmut F. Kaplan, Gibt es eine ethische Weltformel?, Aufklärung und Kritik 2004, S. 226.

29 Ich blende hier die Tatsache aus, dass insbesondere bei einer hohen Dosis auch jüngere Menschen ohne Vorerkrankungen schwer erkranken oder sterben können; vgl. vorn Fn. 5. 
folgenfrei bleiben muss, dürfen wir den angefochtenen Entscheid unter keinen Umständen kassieren.

[21] Jeder der Beteiligten beharrt dabei «dezidiert» auf einem subjektiven Verständnis «seiner» goldenen Regel. Sie haben nach Watzlawick eine Patendlösung gefunden. Dabei handelt es sich um «eine Lösung, die so patent ist, dass sie nicht nur das Problem, sondern auch alles damit Zusammenhängende aus der Welt schafft ${ }^{30}$. Die Beteiligten verfolgen damit wie die Vertreter der Null-Risiko-Theorie und der Herdenimmunität gute Absichten. Allerdings fusst ihr deduktives Denken auf der Überzeugung, ihre Lösung sei derart genial, dass sie alle anderen überflüssig werden lässt. Das kann zu Schäden führen, die von keinem der Beteiligten beabsichtigt wurden.

\section{Abwägen und entscheiden - frei nach Kant}

[22] Zwischen zwei Extremen liegt die Wahrheit selten in der Mitte, sondern ganz woanders. Dass stures Deduzieren bei der Lösung konkreter Probleme selten weiterhilft, lehrt uns unser Berufsalltag. Wie wäre es, wenn wir anstelle von endlosen Deduktionen darauf abstellten, was wir über das Virus tatsächlich wissen und daraus induktiv auf die Zweckmässigkeit unseres Handelns schliessen?

[23] Beginnen wir bei dem, was wir inzwischen wissen. Das Virus verbreitet sich hauptsächlich über Cluster. Die meisten davon bilden sich in schlecht belüfteten Innenräumen. Soll ich damit an die nächste Chorprobe gehen? Selbstverständlich, würde Agamben sagen, ist es ihm doch wichtig, seine Freiheiten nicht aufzugeben. Auf keinen Fall, meinen die anderen, schliesslich gelte es, jeden Toten zu vermeiden.

[24] Kant würde beiden widersprechen. An die Stelle einer falsch verstandenen goldenen Regel stellte er den kategorischen Imperativ. «[H]andle nach derjenigen Maxime, durch die du zugleich wollen kannst, dass sie ein allgemeines Gesetz werde. ${ }^{31}$ Kant fragt so danach, ob man Agambens Grundsatz verallgemeinern könnte. Kann man wollen, dass alle Menschen Agambens Maxime als die ihrige annehmen würden und auch dann zur Chorprobe gehen, wenn die Notfallstationen überfüllt sind? Wohl kaum. Es geht um eine einfache Güterabwägung. So wichtig das Singen für die eigene Gesundheit ist, so wenig scheint es verallgemeinerungsfähig, wenn die Betten auf den Intensivstationen knapp werden. Umgekehrt können wir nicht zu Hause bleiben, bis Milliarden von Menschen geimpft sind. Wir können das Haus durchaus verlassen, müssen dabei aber kreativer werden. Statt zu einer Chorprobe in einem Innenraum treffen wir uns z.B. auf einen Spaziergang. Wir minimieren dabei das Übertragungsrisiko, ohne es ganz ausschliessen zu können. Das Denken im kategorischen Imperativ schliesst Patendlösungen aus.

[25] Mit der kantschen Pflichtenethik machen wir uns das Leben zunächst schwerer. Digitales Denken schliesst sie nach einem zeitgemässen Verständnis ${ }^{32}$ aus. Sollen wir die Weiterbildung

30 Paul Watzlawick, Vom Schlechten des Guten, München 1986, S. 1 (ohne Hervorhebung im Original). Weiterführend Thомаs Stölzel, Staunen, Humor, Mut und Skepsis: Philosophische Kompetenzen für Therapie, Beratung und Organisationsentwicklung, Göttingen 2012, S. 38 f., auch zum Folgenden.

32 Jede Argumentation lässt sich ad absurdum führen. Benjamin Constant provozierte Kant mit dem Beispiel, in dem der Mörder danach fragt, ob man sein potentielles Opfer zu Hause versteckt habe. Kant antwortete trotzig, es sei «ein heiliges, unbedingt gebietendes, durch keine Konvenienzen einzuschränkendes Vernunftgebot, in allen Erklärungen wahrhaft (ehrlich) zu sein»; Immanued Kant, Über ein vermeintes Recht, aus Menschenliebe zu 
vor Ort besuchen oder lieber über den Live-Stream? Sollen wir die Verhandlung durchführen oder auf einen späteren Zeitpunkt verschieben? Was geschähe, wenn wir sie im Einverständnis der Parteien via Videokonferenz durchführten?

[26] Die Fundamentalpositionen bieten hierfür rasche Antworten. Eine Verhandlung über Skype oder Zoom durchführen? Um Himmels willen - der Datenschutz! Oder: Natürlich - die Effizienz! Aus kantscher Sicht würde man demgegenüber danach fragen, ob man wollte, dass eine OnlineVerhandlung nach allseitigem Einverständnis sämtlicher Parteien für die Wochen der hohen Fallzahlen zu einer allgemeingültigen Regel erhoben würde. Bejaht man die Frage, ruft man eventuell Vertreter des Datenschutzes auf den Platz. Verschiebt man umgekehrt eine Gerichtsverhandlung, weil eine der Verfahrensparteien gegenüber einer Online-Variante Vorbehalte anmeldete, werden einen die Kollegen kritisieren, die Verfahrenseffizienz in einem absoluten Sinn verstehen. Selbstverständlich müssen wir die Frage gestützt auf das anwendbare Recht beantworten. ${ }^{33}$ Dort, wo die Fragen nur rudimentär oder gar nicht geregelt sind, lohnt es sich indessen, nach einer allgemeingütigen Regel zu suchen. Letzteres gebietet bereits Art. 1 Abs. 2 ZGB, ${ }^{34}$ wonach wir bei Fehlen von expliziten Vorschriften nach der Regel entscheiden sollen, die wir als Gesetzgeber aufstellen würden.

[27] Das ständige Abwägen macht uns von beiden Seiten angreifbar. Wir sollten das in Kauf nehmen. Es ist wie in der Urteilsberatung zum rechtlichen Gehör. Wenn wir vorschlagen, die Gehörsverletzung ausschliesslich bei den Nebenfolgen zu berücksichtigen, haben wir für die eine Kollegin den Eigenwert verkannt, der den Verfahrensgrundrechten zukommt. Für den anderen Kollegen, der ohne Weiteres heilen wollte, sind wir ein Verfahrensfanatiker. Wenn wir die Lösung, die wir vorschlagen, für verallgemeinerungsfähig erachten, sollten wir an ihr festhalten. Der kategorische Imperativ scheint damit nicht nur für die gegenwärtige Krise, sondern auch für unseren richterlichen Alltag ein guter Ratgeber.

\section{Wirklichkeitskonstrukte dekonstruieren}

[28] Vielleicht erinnern Sie sich an das magische Theater in Hermann Hesses Steppenwolf. Hesses ambivalentes Alter Ego findet sich in einem Korridor mit unzähligen Logentüren wieder. Er betritt eine dieser Logen mit der Inschrift «Anleitung zum Aufbau der Persönlichkeit Erfolg garantiert» ${ }^{35}$. Dort erklärt ihm ein Schachspieler, dass die Seelenlehre der Wissenschaft lückenhaft sei. Er ergänze sie deshalb mit dem Begriff der «Aufbaukunst». Wenn das Ich auseinanderfalle, so der Schachspieler, könne man die Stücke jederzeit in beliebiger Ordnung neu zusammenstellen. «Wie der Dichter aus einer Handvoll Figuren ein Drama schafft, so bauen wir aus den Figuren unseres zerlegten Ichs immerzu neue Gruppen, mit neuen Spielen und Spannungen, mit ewig neuen Situationen».

lügen (1797), in: Werke, Band 8, Frankfurt am Main 1977, S. 351. Das Beispiel zeigt, dass man auch mit der Pflichtenethik mühelos zu Patendlösungen gelangen kann.

Vgl. die Situation im Urteil des Bundesgerichts 4A_180/2020 vom 6. Juli 2020, E. 3.1, wo es an einem beidseitigen Einverständnis für eine Verhandlung per Video-Konferenz fehlte.

34 Vgl. Eugen Bucher, Der von den Juristen verkannte apagogische Beweis - Dazu auch Kant und Kelsen, in: Andreas Heldrich u.a. (Hrsg.), Festschrift für Claus-Wilhelm Canaris zum 70. Geburtstag, München 2007, S. 991 ff., 1006 , 1009. Vgl. auch Arthur MeIer-Hayoz, Der Richter als Gesetzgeber, Zürich 1951, S. 241, der auf Aristoteles verweist.

35 Hermann Hesse, Der Steppenwolf, Frankfurt 1978, S. 208, auch zum Folgenden. 
[29] Der Schachspieler schafft so mit den immer gleichen Figuren auf dem immer gleichen Brett ständig neue Welten. ${ }^{36}$ Die Wirklichkeit wurde jedes Mal eine andere. Das Brett und die Figuren blieben demgegenüber dieselben.

[30] In der Krise sind wir alle Schachspieler. Wir alle ordnen die Figuren etwas anders an. Jeder von uns schafft so seine eigene Wirklichkeit. Der eine Experte rät uns anhand seiner Aufstellung zum Maskentragen. Der andere kritisiert Boris Johnson heftig für sein Ampelsystem. Und noch einer will gar keine Empfehlungen abgeben, da die Daten zu wenig zuverlässig seien.

[31] Für uns Richter ist dies nichts Aussergewöhnliches. Aus unseren Verfahren wissen wir, dass die sogenannt «objektive» Wahrheit meistens im Dunkeln bleibt. Das Strassenverkehrsamt entzieht jemandem den Führerschein wegen eines Augenleidens. Der Mann könne Distanzen nicht mehr korrekt abschätzen, und in seinem Sehfeld bestünden gefährlich grosse blinde Flecken. Der Automobilist wiederum legt uns ein Gutachten vor, das zeigt, wie er die fehlenden Teile seines Sehfelds ohne Weiteres ergänzen kann.

[32] Beide Verfahrensparteien sind nach Watzlawick «Konstrukteure ihrer eigenen Wirklichkeit» ${ }^{37}$. Beide Darstellungen sind aus sich heraus «wahr». Beide sind sie stringent. Selten können wir die eine als vollkommen falsch verwerfen. Vielmehr müssen wir untersuchen, wie die Schachspieler ihre Figuren auf dem Brett positionierten, um die von ihnen konstruierte Wirklichkeit zu erkennen.

[33] Im Frühjahr sagte mir ein Kollege in leicht vorwurfsvollem Unterton, dass ich mich ja überhaupt nicht mehr am Gericht blicken lasse. «Das kannst Du Dir auch nur leisten, weil wir hier die Stellung halten.» Damit hatte der Kollege Recht. Seine Wirklichkeit erschien «wahr». Wenn ich abends oder an einem Sonntag ans Gericht ging, war er nicht dort, und umgekehrt. Der Kollege hielt den Gerichtsbetrieb aufrecht, während ich mich aus seiner Sicht im Schlendrian erging.

[34] Ich hatte mir in der Zwischenzeit ebenfalls meine Wirklichkeit erschaffen. Ich lebte dem nach, was ich damals als kategorischen Imperativ zu erkennen glaubte. Im Nachhinein betrachtet hätte ich wahrscheinlich öfter ans Gericht gehen können. In der Deutschschweiz waren die Intensivstationen nie überlastet. Man musste die Patienten nicht auf den Gängen liegen lassen. Niemand starb, weil es an Beatmungsgeräten fehlte. Insofern war mein Vorgehen falsch und das des Kollegen richtig.

[35] Aber was, wenn es umgekehrt gewesen wäre?

[36] Der britische Epidemiologe Geoffrey Rose beschrieb die beiden unterschiedlichen Wirklichkeiten mit dem Begriff des «Präventionsparadox». ${ }^{38}$ Präventive Massnahmen mögen der Bevölkerung viel nützen; dem Einzelnen bringen sie nur wenig - und umgekehrt. Wir lassen uns gegen alle möglichen Krankheiten impfen, gurten uns im Auto an, usw. Bevor wir in Israel einen Supermarkt betreten, zeigen wir dem Beamten vor dem Gebäude den Inhalt unserer Tasche. Das zu vermeidende Unglück bleibt dabei regelmässig aus. Unsere Sorge schien also unbegründet, ebenso jene des Beamten. Umgekehrt hätte aber auch genauso die Massnahme erfolgreich sein können, die das Unglück zu verhindern suchte, sei es nun das Tragen eines Sicherheitsgurts oder das Öffnen der Tasche. Wir werden es nie wissen. Damit werden wir auch nie schlüssig beantwor-

36 «... [Die] Tonart war verändert, das Tempo gewechselt, die Motive anders betont, die Situationen anders gestellt»; Hesse (Fn. 35), S. 209.

37 Paul Watzlawick, Vom Unsinn des Sinns oder vom Sinn des Unsinns (1992), München 2005, S. 78.

38 Geoffrey Rose, Strategy of prevention: lessons from cardiovascular disease, British Medical Journal 1981, S. 1847 ff., Volltext abrufbar über https://pubmed.ncbi.nlm.nih.gov/6786649/. 
ten können, ob wir zu Beginn der Pandemie öfter zur Arbeit hätten fahren oder zu Hause hätten bleiben sollen.

[37] Fest steht, dass sowohl der Kollege als auch ich unseren Glaubenssätzen erlegen sind. Während der Kollege vom Glaubenssatz ausging, dass der Gerichtsbetrieb zum Erliegen kommt, wenn zu viele zu Hause arbeiten, ging ich davon aus, dass uns die Beatmungsgeräte ausgehen, wenn zu viele am Gericht arbeiten. Mit dem Glaubenssatz ist die Angst verbunden, dass wir auf existentielle Weise scheitern könnten, wenn wir das in dem Satz geforderte Verhalten nicht sofort umsetzen. ${ }^{39}$ In der Krise müssen wir diese Glaubenssätze identifizieren und gegebenenfalls durch angemessenere Gedanken ersetzen. Ansonsten treiben uns unsere Ängste vor sich her. An unserer Pflicht, uns rasch und verallgemeinerungsfähig zu entscheiden, ändert dies indessen nichts; wenn wir unsere Glaubenssätze erkennen, hilft uns das nur dabei, bewusstere Entscheidungen zu treffen.

[38] Die gegenwärtige Krise führt uns vor Augen, dass wir stets Konstrukteure unserer eigenen Wirklichkeit bleiben. Wenn wir uns unsere Glaubenssätze stets aufs Neue vergegenwärtigen, hat dies nach Watzlawick drei Vorteile: ${ }^{40}$

1. Wenn wir wissen, dass wir uns dauernd unsere eigene Wirklichkeit erschaffen, können wir jederzeit eine andere schaffen. Das macht uns freier. Es kann bereits eine befreiende Wirkung haben, wenn wir uns überlegen, aufgrund welcher Faktoren wir uns unsere Wirklichkeiten konstruieren. Vielleicht sind wir dem Home-Office gegenüber offener eingestellt, weil wir keine Kinder haben. Oder wir misstrauen Quarantäne-Vorschriften, weil wir das Reisen lieben. Machen wir uns unsere möglicherweise verzerrte Wahrnehmung bewusst, können wir unsere Wirklichkeit eher neu konstruieren.

2. Indem wir uns unsere Wirklichkeiten bewusstmachen, werden wir im tiefsten ethischen Sinn verantwortlich. Denn wer tatsächlich begreift, Konstrukteur seiner eigenen Wirklichkeit zu sein, findet weder in Sachzwängen noch in der Schuld des anderen eine Ausflucht. Wir können uns in der Krise damit nicht darauf berufen, dass der Bundesrat (die kantonale Regierung, die Gerichtsleitung usw.) dies oder jenes anordnete oder diese oder jene Anordnung unterliess. Wir allein sind für unser Handeln verantwortlich. Gerade als Richter sollten wir nicht darauf warten, bis uns jemand sagt, was wir tun sollten. ${ }^{41}$

3. Wenn wir uns die Konstruktion unserer jeweiligen Wirklichkeit eingestehen, werden wir konzilianter. Denn wenn wir wissen, dass Wirklichkeiten blosse Konstrukte sind, werden wir unseren Mitmenschen vergeben, dass sie daran herumwerkeln. Wenn mich mein Gegenüber kopfschüttelnd fragt, wie ich zu Hause arbeiten kann, sollte ich mir vergegenwärtigen, dass er mit einer kinderreichen Familie in einer völlig anderen Welt lebt als kinderlose Doppelverdiener.

[39] Watzlawick räumt ein, dass es nur wenige Menschen gebe, die so weit kommen. Aber wir können es dennoch versuchen. Wenn wir uns erst einmal eingestanden haben, dass wir uns ständig

39 Die Literatur zur Resilienzforschung ist kaum mehr zu überblicken; vgl. nur Jutta Heller, Resilienz, Innere Stärke für Führungskräfte, Zürich 2015, S. $121 \mathrm{ff}$.

40 Watzlawick (Fn. 37), S. 79.

41 Ein deutscher Verwaltungsrichter brachte es mal mit dem schönen Diktum auf den Punkt, dass Richter keine Chefs hätten. 
eine neue Wirklichkeit konstruieren, werden wir die nächsten Krisen vielleicht etwas gelassener überstehen.

\section{Stille ertragen}

[40] David Bohm (1917-1992) war ein brillanter Quantenphysiker. Er stellte die herrschende Orthodoxie seines Fachs wiederholt in Frage. Sein Problem war, dass er mit Widerspruch schlecht umgehen konnte. So konnte man aus seinem Büro am Londoner Birbeck College immer wieder lautes Schreien vernehmen. Jedermann wusste in solchen Momenten, dass es ein Student gewagt hatte, Bohms Erklärung der Quantentheorie in Frage zu stellen.

[41] Der junge Mann, der die Zeit nach Bohms Vorlesung dazu nutzte, um ostentativ nachzufragen, hatte von Bohms Temperament offensichtlich nichts mitbekommen. Es kam zum Eklat. Mittendrin hielt Bohm plötzlich inne. «Das Problem ist, dass wir nicht kommunizieren. Was machen wir jetzt?» ${ }^{42}$ Nach dieser Frage verfiel der Physiker in tiefes Schweigen. Die Zuhörer waren ratlos. Es schien, als ob Bohm darauf hoffte, auf eine nicht-konfrontative Weise zu einem Austausch mit dem jungen Kollegen zu finden.

[42] Bohm nutzte den Eklat zu einer kleinen Schrift über den Dialog. ${ }^{43}$ Im Kern fordert er darin, dass wir unserem Gegenüber wertschätzend zuhören, ohne sogleich in Kategorisierungen zu verfallen. ${ }^{44}$ Bohms Gedanke fand Eingang in die Managementliteratur, ${ }^{45}$ und viele Unternehmen und Organisationen unterhalten heute Gesprächsgruppen, wie sie vom Physiker ins Leben gerufen wurden. ${ }^{46}$

[43] Nun kann es uns schwerfallen, nicht sogleich zu werten. Wir sind von Berufs wegen zum dauernden Kategorisieren konditioniert. In Parteivorträgen suchen wir nach Beweisvorbringen. Rechtsschriften klopft unser Autopilot auf versteckte Verfahrensanträge ab. In unserem richterlichen Alltag kann uns das durchaus weiterhelfen. Wenn es hingegen darum geht, genau hinzuhören, kommt uns das dauernde Kategorisieren in die Quere. Durch das ständige Einordnen diskutieren wir im Sinn des Wortes: ${ }^{47}$ Wir zerlegen die Argumente unseres Gegenübers in ihre Einzelteile. Es ergeht uns dann wie Bohm am Ende seiner Vorlesung. Wir mögen Recht behalten haben. Was uns unser Gegenüber aber eigentlich sagen wollte, entgeht uns. Weil wir das Gesagte sogleich Kategorien zugeordnet und in seine Einzelteile zerlegt haben, hat es wie eine Uhr aufgehört, zu funktionieren.

42 Vgl. David Peat, Infinite Potential. The Life and Times of David Bohm, 1997, S. 244, auch zum Folgenden. Übersetzung M.K.

43 David Вонм, On Dialogue (1996), London/New York 2004 (deutsche Übersetzung: Der Dialog, Das offene Gespräch am Ende der Diskussion, 9. Aufl. 2019).

44 Вонм (Fn. 43), S. 6 ff., 59 ff. Die Position war selbstverständlich keineswegs neu; vgl. nur Kenneth Cissna/ Rob Anderson, Theorizing about Dialogic Moments: The BuberRogers Position and Postmodern Themes, Communication Theory 1998, S. $63 \mathrm{ff}$.

45 Vgl. statt vieler Peter M. Senge, The Fifth Discipline: The Art and Practice of the Learning Organization, New York 1990, S. 239 ff., seither in zahlreichen Neuauflagen erschienen (6. Aufl. New York 2006). Die deutsche Übersetzung wurde ebenfalls ein Bestseller; Peter M. Senge, Die fünfte Disziplin: Kunst und Praxis der lernenden Organisation, 11. Aufl. Stuttgart 2017.

46 Vgl. etwa Laura W. Black, Building Connection While Thinking Together: Byproducts of Employee Training in Dialogue, Western Journal of Communication 2005, S. 273 ff. Vgl. auch Thomas KLUG, Classics of Organisational Research: David Bohm, Organisationsentwicklung 2018, S. 90 ff. 
[44] Bohm empfiehlt anstelle der Zerlegung in der Diskussion den Dialog. Durch etwas (dia) den Sinn erkennen $(\log o s)$. Das ist das Prinzip des Bohmschen Dialogs. Wir bleiben dabei beim grösseren Ganzen, das uns unser Gegenüber mitteilen will. Wir verharren in der respektvollen ${ }^{48}$ Beob- $^{-}$ achtung, statt gleich zu kommentieren. Bohm empfiehlt uns, dabei auf unsere inneren Überzeugungen zu achten. ${ }^{49}$ Ähnlich wie bei Watzlawick sollten wir uns also vergegenwärtigen, anhand welcher (verzerrten) Überzeugungen (bias) wir unsere Wirklichkeit konstruieren.

[45] Die gegenwärtige Krise ist damit eine gute Gelegenheit, besser hinzuhören. Vielleicht gelingt es uns beim nächsten Mitarbeitergespräch, Schweigen besser auszuhalten. Unser Gegenüber mag den Moment nutzen, um uns auf Schwächen bei der Führung unseres Teams hinzuweisen. Vielleicht schauen wir beim nächsten Mal etwas genauer hin, wenn eines unserer Urteile kassiert wird. Die obere Instanz wollte uns eventuell etwas zwischen den Zeilen mitteilen. Danach zu suchen, ist weniger bequem, als den Kollegen der Rechtsmittelbehörde fehlendes Verständnis oder blankes Unvermögen zu unterstellen. Es bringt uns aber weiter als das Verharren in unserer Position. Möglicherweise gelingt es uns, bei der nächsten Krise genauer hinzuhören und damit Fundamentalpositionen schneller aufzulösen. An den Gerichten scheint das umso wichtiger, als wir uns unsere Kolleginnen und Kollegen nicht aussuchen können und mit ihnen auf Dauer produktiv zusammenarbeiten müssen.

\section{Zutrauen finden}

[46] Unser Beruf kann uns auch in anderer Hinsicht in die Quere kommen. Zivil- und Strafrichter sind es sich gewohnt, den Vorbringen der Parteien mit einer Portion Skepsis zu begegnen. Was behauptet wird, ist noch lange nicht bewiesen. Wir Verwaltungsrichter wiederum müssen den Behauptungen der Exekutive von Berufs wegen mit Zurückhaltung begegnen. Sinn des Verwaltungsprozesses ist es schliesslich, dass sich der Private und die Behörde zum ersten Mal auf Augenhöhe begegnen können. Würden wir Regierung und Verwaltung blind vertrauen, hintertrieben wir den Sinn der Verwaltungsgerichtsbarkeit.

[47] In der Krise kann uns unsere antrainierte Skepsis zum Hindernis werden. Wenn uns unsere Mitarbeiter sagen, dass sie im Home-Office besser arbeiten können, sollten wir dies nicht als Erstes hinterfragen. Wenn wir selbst zu Hause arbeiten, sollten wir jenen vertrauen, die vor Ort geblieben sind. Wenn wir im Büro arbeiten, sollten wir uns von dem Gedanken lösen, dass unsere Kollegen ihre Zeit ausserhalb des Büros vertrödeln.

[48] Die Erfahrungen aus dem Normalbetrieb mögen uns dabei helfen. Bei der Prozessleitung arbeite ich mit meinen Gerichtsschreibenden nach dem Modell des Cockpits zusammen. Mein Mitarbeiter behält die Instrumente im Auge und sagt mir, wenn wir zu tief fliegen oder vom Kurs abkommen. Er ist mein Kopilot. Ich fliege den Prozess im Wissen darum, dass mein Gerichtsschreiber für das Wohlergehen unserer Passagiere, der Verfahrensparteien und ihren Anwälten, das Beste will. Meine Skepsis spare ich mir für den Moment auf, in dem ich mich mit den Behauptungen der Verfahrensparteien inhaltlich auseinandersetze.

$48 \operatorname{Re}(-)$ spectere: erneut hinschauen, beobachten.

49 Вонм (Fn. 43), S. $59 \mathrm{ff}$. 
[49] Zutrauen bedeutet, Regeln abzubauen. Es macht keinen Sinn, unsere Mitarbeiter mit Vorschriften zu überziehen, wie sie im Home-Office zu arbeiten haben. Stattdessen sollten wir allein die Ziele vorgeben, nämlich dass Urteile und Instruktionsverfügungen auch im Home-Office prägnant ausfallen und innerhalb angemessener Frist ergehen. ${ }^{50}$ Dass wir die Wirtschaft vor Schaden schützen, indem wir gesund bleiben. ${ }^{51}$ Dass wir andere dadurch schützen, indem wir Abstand halten und eine Maske tragen, wenn wir ans Gericht gehen.

[50] Um anderen etwas zuzutrauen, müssen wir zunächst einmal uns selbst vertrauen. ${ }^{52}$ Dafür braucht es keine umfangreichen Regelwerke. Der CEO von Netflix etablierte in seinem Unternehmen eine Kultur des Vertrauens, indem er Regeln auf ein Minimum reduzierte. ${ }^{53}$ Wir können an den Gerichten ebenfalls Reglemente abbauen. Es ist zwar normal, wenn wir in einer Stresssituation ins Mikromanagement verfallen. Aus diesem Zustand müssen wir jedoch während der Krise schnell wieder herausfinden. ${ }^{54}$

[51] Zutrauen bedeutet in diesem Zusammenhang nicht, schwarmdumm zu werden. Zutrauen bedeutet, genau hinzuschauen und anschliessend die anderen ihre Arbeit machen zu lassen. Dafür braucht es ein gewisses Grundvertrauen in unsere Abteilungspräsidien, die Gerichtsleitung und vielleicht auch unsere Regierung, dass sie das Richtige machen wollen. Von blindem Vertrauen ist ein solches Zutrauen weit entfernt. Vor allem aber entbindet es uns nicht unserer Pflicht, zu handeln, bevor uns jemand sagt, was wir machen sollen. ${ }^{55}$

\section{Alles Leben ist Lernen}

[52] Die nächste Krise ist vielleicht kein Virus mehr. Eventuell geht uns für Monate der Strom aus. Dann müssten wir vielleicht das Gegenteil dessen machen, was wir jetzt tun. Statt zu digitalisieren müssten wir wieder lernen, vermehrt analog zu arbeiten.

[53] Die Grundprinzipien bleiben aber jene, die sich in der jetzigen Krise bewährt haben. So banal es klingen mag: Als Erstes müssen wir akzeptieren, dass es eine Krise gibt, und dass sie während Monaten, vielleicht Jahren, mit Unsicherheiten einhergeht. Wir müssen rasch handeln und dabei fortlaufend die Patendlösungen entlarven, die uns von (selbsternannten) Experten vorgetragen werden. Bei unserem Handeln sollten wir uns als Drittes überlegen, was davon verallgemeinerungsfähig erscheint. Wenn wir danach als Viertes erkannt haben, welche Wirklichkeiten wir konstruiert haben, gelingt es uns fünftens, besser zuzuhören. Dadurch ergibt sich als Sechstes mehr Vertrauen in unser Umfeld. So besiegen wir unsere Berufskrankheit, ständig das letzte Wort haben zu wollen.

50 Damit müssen wir einen Weg finden, auch dann rasch auf Eingaben der Parteien zu reagieren, wenn wir physisch nicht am Gericht sind. Ich selbst bin dazu übergegangen, die Parteien öfter mal anzurufen und die Verfügung anschliessend schriftlich nachzuliefern.

51 Der Schutz der Wirtschaft und jener der Gesundheit sind dabei jedenfalls dann keine Gegensätze, wenn man sich von Fundamentalpositionen und den damit einhergehenden Patendlösungen entfernt; vorn Fn. 21.

52 Anschaulich Charles Pépin, Sich selbst vertrauen: Kleine Philosophie der Zuversicht, 3. Aufl., München 2019, insbes. S. $17 \mathrm{ff}$. 
[54] Aus diesen sechs Erkenntnissen ergibt sich eine siebte. Krisen sind dazu da, dass wir ständig dazulernen. Wir wissen heute über das Virus ungleich mehr als zu Jahresbeginn. Um diese Krise zu bewältigen, müssen wir weiter lernen. Es reicht dafür nicht aus, uns nur aus einer Quelle zu informieren. Wir müssen mehrere Zeitungen studieren, mehrere Radiosender hören und die verschiedensten Bücher lesen. Dafür gibt es keine Ausrede. Wir müssen uns die Zeit nehmen, um uns selbst ein Bild zu machen. Erst dann besteht überhaupt die Chance, unsere vorläufige Konstruktion unserer Wirklichkeiten besser zu durchschauen.

[55] Die Münchner Philosophen Nikil Mukeriji und Adriano Mannino mahnten uns zu Beginn der Krise, dass wir im Hinblick auf die nächste Krise mehr auf Vorrat nachdenken sollen. ${ }^{56}$ Es geht damit nicht nur darum, die gegenwärtige Pandemie in Echtzeit zu bewältigen, sondern uns besser auf eine andere Krise vorzubereiten. Die Zeiten, in denen Richter ihren Beruf bis ins Pensionierungsalter ausübten, sind vorbei. Das ständige Lernen geht damit über das reine Sachwissen weit hinaus. Vielleicht nutzen wir die gegenwärtige Krise, um an unseren ausserfachlichen Kompetenzen zu arbeiten. Oder wir besuchen eine Online-Weiterbildung, schreiben ein Buch oder lesen wieder mehr. Wie wir dazulernen, ist im Grunde unbedeutend. Entscheidend ist allein, dass wir neugierig bleiben. ${ }^{57}$ Und dass wir auf diese Weise erfahren, dass alles Leben lernen ist. ${ }^{58}$

Dr. iur. MARTIN KAYSER, Richter am Bundesverwaltungsgericht und Lehrbeauftragter an der Universität St. Gallen.

Ich gebe hier allein meine persönliche Auffassung wieder. Ich danke David Aschmann, Julian Beriger, Marianne Ryter, Marc Steiner und Jonas Wüthrich herzlich für ihre wertvollen Anregungen. Verbleibende Irrtümer sind allein mir zuzuschreiben.

56 Nikil Mukeriji/Adriano Mannino, Covid-19: Was in der Krise zählt, 4. Aufl., Stuttgart 2020, S. 63 ff.

57 Dazu, was Neugier für unser berufliches Fortkommen ausmacht, IAN LesLie, Curious, London 2014, S. 125 ff.

58 In Anlehnung an KarL Popper, Alles Leben ist Problemlösen (1994), Berlin 2006. 